\title{
A Study on Tactics in Using Talents
}

\author{
Xiangdong Ma \\ School of Management, Guangdong Vocational College of Science \& Trade \\ Guangzhou 510640, China \\ E-mail: mysheng@gmail.com
}

\begin{abstract}
In various cases of using talents, the tactics in using talents win special attentions and stresses of politicians, thinkers, militarists, strategists, scholars and even common people in generations. This paper has put forward the system of tactics in using talents, and generalized the core content to nine aspects, namely self-using, observation, selection and recommendation, integrated using, borrowing strength, inspiration, ruling, retaining, train and education. This paper has analyzed the nine aspects compactly, and pointed out the purpose and meaning in studying and researching these tactics.
\end{abstract}

Keywords: Tactics in using talents, Self-using, Observation, Selection and recommendation, Integrated using, Borrowing strength, Inspiration, Ruling, Retaining, Train and education

\section{Put Forward}

What is tactic? The word of "tactic" was first seen in the book of "Three Kingdoms' Record" in China. The author Shou Chen appraised Yu Chen and Jia Guo as "Talented and tactical, the thaumaturge of the world" in "The book of Wei". And in "The book of Wu", he appraised Xun Lu as "Xun Lu's tactics make me astonish, and the ability to recognize talents of Quan Sun makes me acclaim. So they can make huge accomplishment". This word is to commend the militarists who are bellyful of knowledge.

"The book of Han------the Record of Art and Literature" has separated ancient Chinese military book as four species, namely the leadership strategy of military, the situation of military, the two sides of military, the techniques of military. Leadership strategy means tactic. "The Record of Art and Literature" has given an explanation of the leadership strategy of military as "The leadership strategy is the skill to manage a country, to control the army, to know the situation and the two sides of things". We can find out the abundant meaning of tactics through these famous words.

Xiang Liu, who was the famous author in the Han Dynasty, pointed out that "Tactics have two sides, the better tell the fate, and the next tell the affair. Which tell the fate can foresee the root of live or death and fortune or disaster. They help people to know the rise and fall at the first beginning, to prevent before the accident, and to take refuge in immateriality. Which tell the affair are also not bad. They help people to recognize gain and loss at the beginning of accident, and to find the reason. So people will not be defeated. That's the essence of tactics.

Wanli Chang puts forward the theory in the "Ideas Man's Secret" that strategy has six levels, that are tiny skill, with intellect, through quiet, concrete, sit-in meditation and meditation according to its different levels. The appearance, feature and content of each level in the six levels of the strategy are not all of the same. "Tiny skill" level is the "point", like "spot", the influential power of which is limited. The strategy of "with intellect" and "through quiet" levels can reach the thought realm of "segment" or "side", but still be partial. The "concrete" strategy is just the overall one and has a physical truss of strategy. To reach the "sit-in meditation" thought realm, it is not only a physical truss but enters the core from the surface, and surpasses the physical appearance to enter the "meaning" world. As for "meditation" strategy, which is a level higher than "sit-in meditation", it runs through "spirit" into the strategy body, so as to make the strategy body get rid of external creation and become an individual life that can produce self demands inside. Once the strategy of this level is put to use, its power always exceeds the commanding scope of strategy subject. It seems that a trend of power forces all the subjects and objects to act. It can be seen from the above that the strategy has different levels and the thought realm is profound.

As to the definition of tactic, different person has different opinion. I prefer the definition written by Bingyan $\mathrm{Li}$ in the book "The discrimination of tactic's definition" through research and comparison, which is "Tactic is decision-makers' brain, wisdom and capacity, stratagem in competition. It helps decision-maker forecast the future, grasp chances, plan as a whole, tend towards benefit and avoid harm".

Tactic in using talents is an old and renewable subject. It has win special attentions and stresses of politicians, thinkers, militarists, strategists, scholars and even common people in generations. Recently, through studying the tactic monograph at all times and in all over the world and the monograph written by leaders and worthy, and the 
employment practice of Chinese and foreign companies, I consider that the main content of researching tactics in using talents is the stratagem in using talents' field. The system of tactics in using talents includes nine aspects, namely self-using, observation, selection and recommendation, integrated using, inspiration, borrowing strength, ruling, retaining, train and education. These nine aspects combine together and form an integrated and organic body. From these nine aspects, we can understand and master the contents and essence of tactics in using talents systematically, precisely and completely.

\section{Content}

\subsection{Self-using tactics.}

For employers, making better use of talents, the first requirement it to make better use of themselves. To create talents first create themselves. On one hand, the success or failure in using talents' activities, lies on the diathesis and tactics of employers. On the other hand, the employers also have the problem of being used. Because all conductors have two attributes, to underlings, they are leaders, and to their boss, they are the person being used. Employers also have two attributes, which are using talents and being used. So the employers must first consider the problems of being used in using talents' activities. The self-using tactics are the stratagems of using oneself, which include three aspects:

The first is the diathesis and culture of employers. The diathesis and culture of employers means that the employers must be provided with high diathesis, such as good psychology diathesis, abundant knowledge, modern conception, high political quality, strong compositive quality, and healthy physique. Employers must advance all these diathesis, enhance compositive quality. That is the basic of using talents. You must remember, if the employers are demoralization, narrow-minded, wacky, narrow-gauge, lose loyalty when seeing benefits, and have no faith, their want to make better use of talents means nonsense. So, the employers should advance all kinds of diathesis continually and insistently, take effort to achieve the new ambit and high level. Only in that way, they can make good use of talents, and make success. In this aspect, self-using tactics include all-conquering when no desire, incorruptibility, modest and careful, be admired by personality, not be frightened before accident, be faithful, and accept other's opinion with an open mind and so

The second is that the employers should master the self sale promotion skills. The employers should be good at sale promotion in any occasion. To let others admit their ability, and to let their boss know their clinging pursuance and responsible quality. So that their boss will provide them all kinds of opportunities and good working environment, in order to let them make outstanding achievement and miracle. In this aspect, self-using tactics include volunteer one's services, seek for breach, self sale promotion, choose boss to follow and so on.

The third is to hide. When using talents, the employers may sometimes encounter jealous and offensive leaders, and stay in an adverse circumstances which are full of danger, cautiousness, and abandon. In such adverse circumstances, employers should take the self-using tactic, which is to hide.

Such as "The best is to tolerance". Human beings have emotions. Their feelings are often subject to the external environment and internal desire of interaction. If these effects can be properly controlled, it may switch disaster to lucky. Otherwise, they might endanger themselves because of anger. Tolerance for the major includes: First, when facing threat, you should tolerant. Second, when being humiliated, you should tolerant. Third, when facing money, honor and desire, you should tolerant. Forth, when proud, you should tolerant. Fifth, when anger, you should tolerant. In short, to tolerant what others can't tolerance. Many famous person set "tolerance" as their exploits and achievements in social motto. In "Romance of the Three Kingdoms", Yi Sima becomes a merit because of his strong power on tolerance. Face Cao Cao's discrimination and oppression, tolerance and colleagues excluded frame-up, the wise forbearance "women humiliated" Junior tolerance of bullying Shuang Cao, a firm resolute map's exploits have come. A "forbearance" of Sima Yi throughout the entire life, it has also fostered an eternal Dili Sima Yi. Numerous facts have proved that people can not emotion, the patient Department to be patient. Only then can we deal with it sensibly, calm, fair and appropriate, can accomplish a great deal.

\subsection{Tactics in observation is a strategy and general plan of observation and discerning talents.}

Tactics in observation is one of the parts of the foundation of employees' managering and it's also the basic precondition which should be focused on of study and mastering employees managering systems. The using of Tactics in observation is also the basic ability which should be made efforts on of employer. To treat Tactics in observation like what is mentioned above is because employees managering require the employer knows how to observe an employee. In other words, employer must research, analyse, understand and know the employees' quality on various fields and unique skill well, and must distinguish the characteristic, specialty and ability and political integrity situation of the employees, and ensure the information collected is much enough, deep enough and correct enough to build the foundation of succeeding in employees' managering and to lead the employer choose the 
appropriate employees ,arrange them to the position which could make their ability's function most, max the power of people and objects, get the good achievement of employees' managering, and win a unassailable position while competing in various fields.

The research of view strategies can be started with the following three aspects: first, the traditional view strategy passed down from the ancientry; second, the strategy to identify and view talents by psychology, behavioral science and other knowledge, and modern telecommunications means; third, the view strategy put forward by modern leaders and prominent figures, and frequently used in modern employment practice.

As Seven View Methods: Seven View Methods was put forward in the "Way of the General" (Jiang Yuan) by Liang Zhuge to identify and view employers.

(1) Ask him right and wrong for his ideal; Ask him about right and wrong to view his ambition.

(2) Examine him questions for his ability to take action; Argue with him to view his resourcefulness and eloquence.

(3) Consult him resourcefulness for his knowledge level; Discuss stratagem with him to view his wisdom.

(4) Assign him difficult work for his courage; Confront him with disaster and hardship to view his courage.

(5) Drink him wine for his nature; Make him drunk to view his nature.

(6) Chance him benefit for his probity; Seduce him with benefit to view his probity.

(7) Entrust him work for his credit. Appoint him a task to view his credit.

The view strategies mainly include seven view methods, observe tiny things for its trend, eight view methods, imagining the big from the small, nip in the bud, methods of detecting treacherousness and other methods.

\subsection{Electing and Recommending Strategies.}

In the Romance of the Three Kingdoms, Yuanzhi went straight to recommend Liang Zhuge and Liang Zhuge recommended Tong Pang, which had been widely read by the people. The behavior that "talent should be the sole standard" and knowing and recommending talents was the characteristic of the outstanding figures in past dynasties. Electing and recommending talents have been the noble quality of employers. Employers should identify personnel and recommend talents. Only by recommending talents, can the talent be put to good use and can the business be developed. During using the personnel, employers should identify and view to find talents in each aspect, and to recommend those talents for the leading department of each layer with high responsibility and enterprise, then let them play their roles in each key department, which is the requirement of developing the business and also an important element of employment strategy.

Knowing and recommending talents. A typical example was that $\mathrm{Ze} \mathrm{Kan} \mathrm{of} \mathrm{Wu}$ Kindom recommended Xun $\mathrm{Lu}$ in the Romance of the Three Kingdoms. In A.D.222, in order to reseize Jing Zhou and revenge for Yu Guan, Bei Liu led on 100 thousand soldiers himself to go to the east, went deep into the border of Wu Kindom for five or six hundreds miles, and besieged the Yi Ling city defended by Heng Sun of East Wu. The armies and civilians of East Wu were in a state of anxiety and the situation was serious. Just at this moment, Ze Kan came out to recommend Xun Lu as the chief commander. He said to Quan Sun, "Emperor, why not use Xun Lu? His talent is not less than Yu Zhou. To reseize Jing Zhou and to defeat Yu Guan are all his ideas. Now facing the formidable enemy, if you could use him, we must defeat Shu Kingdom. In case of any loss, I'd like to bear the imputation together."

Ze Kan said firmly, but that was greatly difficult. Although Xun Lu had been over 40 years old, he was still "so young" in the grand old men's opinions of East Wu. In addition, people always regarded him as an "intellectual" not a generalship. As a result, Ze Kan referred to it just now, Zhao Zhang, Yong Gu and other people opposed immediately. They thought if Xun Lu was assigned, all the generals would not obey that might result in disorder and delayed the great event. At that time, Ze Kan was anxious urgently and spoke loudly, "If not using Boyan Lu (Xun $\mathrm{Lu}$ ), East $\mathrm{Wu}$ must be defeated. I guaranteed him by my whole family." Then, Quan Sun noticed to use Xun $\mathrm{Lu}$ uncompromisingly, and according to Ze Kan's opinion, celebrated by building an altar to worship the general and favored him a sword for authorization. Finally, Xun Lu won the Yi Ling War for East Wu.

The strategy of knowing and recommending talents mostly inspires us two points, one is to know people, with enough understanding on talents; the other is to recommend with smart methods and the employers like to accept and put the talents in an important position.

Electing and recommending strategies include putting forward worthy persons, "talent should be the sole standard", knowing and recommending talents, recommending including enemies outside and relatives inside, and recommending talents with both ability and political integrity, and etc.

\subsection{Tactics of integrating the talents.}

It is the tactics of uniting and using talents. Firstly, integrate various talents to work for employers. Secondly, by 
giving proper work suited to his abilities, exert the maximum effect of the talents. In the profound and unpredictable fields of using talents, integrating the talents is the most important content. At all times and in all over the world, the leaders and outstanding persons are always proud of their ability of integrating the talents. These wonderful foresights have left a lot of excellent tactics of integrating the talents to the later generations.

For example, hire employees with unbeatable salary. That means offering excellent salary attracts the employees. It is a popular method in America. In 1945, the allied forces conquered Berlin. Soviet Russia troops delivered all the German mechanical machines back to Russia. While, America government sent a few planes to Germany to take a lot of German scientist and senior engineers to America as prisons of war. After being assessed, they are hired with very good salary. Using this method, America integrated a lot of talents. As we all know, Kissinger is Jew, Brzezinski is Polish, and Brown Michell is Jewish refugee. They are all brilliant politician of America. There are more examples of scientist. During the Second World War, among ten professors, such as Fermi, who help America develop scientific researches, only one is American. Among winners of Nobel Physics Prize, six people immigrated from Europe. There are a lot of foreign engineers, even $1 / 3$ of them are Chinese, who involved in the famous event, i.e. Apollo Luna Landing. According to the statistics, from 1946 to 1974, America hired 240,000 foreign senior scientist, engineers and doctor with excellent salary. The American assistant secretary of state, Mr. Holland, disclosed that America gained \$12 billion profits from other countries. (The government should consume $\$ 50,000$ per person to complete his education from primary school to university in America. So 240,000 will consume $\$ 12$ billion.)

Not only America government, but also America corporations pay importance to hire employees with unbeatable salary. One Swiss graduate student developed an electronic pen and assistant equipments, which can correct the infrared photos taken by remote sensing satellite. This significant invention caught eyes from the entire world. One American corporation immediately contacted this inventor and persuaded him to work for this company with excellent salary. But, some Swiss companies tried to hold him as well. So, both sides wanted to have this talent and his invention by offering better salary. Finally, clever and adventurous American said: "All right, we will not increase the salary step by step like Swiss company. However, we will give you 5 times of salary offered by Swiss company regardless of how much it is." Eventually, this graduated student went to America with his invention. At the current knowledge and economic times, hiring the employees with excellent salary still is an important tactic. The employers should know it very well.

Tactics of integrating the talents includes using employees with talents, using the talents properly, making the same purpose, controlling key point, respecting talents, using talents without doubt, learning from others' strong points to offset one's weakness, using talents in accordance with their abilities, using talents at proper time, luring the enemy away from his base, being good at making friends and encouraging competition.

\subsection{Tactics of asking for resources.}

Using the talents intrinsically is how to ask for resources to make the employees exert all their strength and talents unreservedly. It is a good fortune and basis of achieving career successfully that asking for resources from human, material, heaven and earth, superior, junior and colleagues to achieve the success of using the talents. At all times and in all over the world, the leaders always attach importance to the tactics of asking for resources. They showed the superb skills of using talents. Some of them even have high degree of professional proficiency.

For example, make use of other person to get rid of an enemy. In The romance of Three Kingdoms, Bei Liu used to hold Xu State. However, because Fei Zhang was addicted to drinking, Bu Lv seized an opportunity to take Xu State. Bei Liu had to settle his troops at Xiao Pei which is near to Xu State. Cao Cao sent a letter to Bei Liu, and ask him to watch for a chance to raid $\mathrm{Bu} \mathrm{Lv}$. Unfortunately, this letter was intercepted by Bu Lv. Bu Lv was so angry that he attacked Bei Liu. At that time, the military strength of Bei Liu was very weak, so he asked for resource from Cao Cao. Cao Cao led his troops and seized Bu Lv at Pi City. Bundled Bu Lv was sent under escort to Cao Cao. He said to Cao Cao:" What you are worrying is only me. But now I have surrendered to you, so you have nothing to worry. I am willing to assist you to get the whole country." Cao Cao heard what Bu Lv said and hesitated to make a decision. Bei Liu said to Cao Cao:” Do you forget that Bu Lv served Yuan Ding and Zuo Dong before?" Cao Cao heard it and made a decision to kill $\mathrm{Bu} \mathrm{Lv}$. Bei Liu made use of Cao Cao to get rid of his enemy, also Cao Cao wouldn't make $\mathrm{Bu} \mathrm{Lv}$ work for him. So it is a great idea.

Tactics of asking for resources includes making enemy work for us, making use of other person to get rid of an enemy, using others' resources, using pretext of god, sailing boat with wind, borrowing chicken to make eggs and having follower on the trees.

\subsection{Tactics of inspiring the talents.}

It is necessary for the employees to have the endless motivity. At all times and in all over the world, the successful 
employers are the superior of inspiring the talents. They are good at using these tactics, and each has his strong point.

For example, inspire the employees with affection. In March, 1642, the captured leader of Ming troop, Chengchou Hong, would never surrender, regardless of how Taiji Huang persuaded him. When Taiga Huang could find no way out, Fey Zhuang offered him a wonderful idea as follows.

One night, after several days without any food, drowsy Chengchou Hong was lying in the bed with closed eyes. Suddenly, the door was opened and one person was walking to his bed gently. He was not interested in it at and kept on sleeping without opening his eyes. He just felt that person slowly sat on the bed side and coved his quilt slightly. After long time silence with sweet-smelling, Chengchou Hong was wondering why this person came here. He opened his eyes slightly and saw a peerlessly beautiful lady with the lotus-face and willow-waist wearing Manchu suits. She was holding a kettle with her pretty hand and watching him tenderly. After several extremely stressful days, a pretty woman suddenly stood in front of him, he could not sir and eyelid any longer and asked:" Who are you? Why do you come here?" The lady answered with a smile:" Because I know you are belt-spirit and I respect you, I come to serve you." He had been feeling lonely for long time since he was caught. It was for him that one day seemed like a year. So, it was really good chance to relieve his loneliness by chatting with such a beautifully woman. The lady asked him how he was caught and the current conditions of his relatives with warmly care and sympathy, by which the grieved memory in his deep heart was called to his mind. His eyes were full of tears. The lady also wept for his sufferings. Then he felt so comfortable and tasted the soup. Surprisingly, he knew it was superb healthy gen-seng soup. He was really grateful to the lady and asked again:" Why do you serve me like this? Who on earth are you?" The lady had to tell him the truth:" I am the imperial concubine, Your Majesty let me serve you." As soon as he heard it, he quickly got up and fell down feelingly. Fei zhuang supported him stand up with a smile and said:" Your Majesty respects your knowledge, so he asks me to console you. Your Majesty don't have other purposes, please don't think too much and feel free." At the same time, she was intended to observe the hint given with his eyes. Chengchou Hong shook his head slightly with a sigh and kept silence. Fei Zhuang noticed his embarrassment and said:" Actually, Your Majesty is not intended to invade your country. So Your Majesty sent a few letters to Emperor Ming to make a peace. However, perversity Emperor Ming trusted absurd words and kept sowing dragon's teeth. If you can be in charge of the process of making a peace, the people of both countries can avoid the chaos caused by war. It should be a boundless beneficence. You can write a letter to Emperor Ming, and inform him that although your body is in Man State, your heart is still in your country. At this stage, a civil strife is happening in Dynast Ming. As Emperor Ming believes you are intervening for your country, he definitely will not put your relatives in trouble. Therefore, it is a satisfactory to both sides. i.e. your country and your family."

With her tender and care, Fei Zhuang relieved his wariness. Her sympathetic words recalled his sufferings. Further, she could put herself in his position and made him feel touched. Eventually, Chengchou Hong was influence by the passion of Fei Zhuang and was most willing to work for Taiji Huang and became a loyal and devoted great idea man. Fei Zhuang used affection to change the behavior of Chengchou Hong and resolved this nail-biting problem.

Tactics of inspiring the talents includes inspiring the talents with songs, killing leader and awarding humblers, awarding one to inspire others, awarding people according to their contributions, punishing one to warn others, simulating person, career inspire and emotional inspire.

\subsection{Tactics of leading the talents is how to guide the senior employees.}

How to control the important employees, master their information clearly, lead and inspire them to lead other employees and make them forward as planned is the content of tactics of leading the talents. By using these tactics properly, the employers can unite the knowledgeable person and employees as an unconquerable and invincible group to go through fire and water for them.

For example, one of these tactics is make a psychological attack as priority. For any conduct of using talents going on wheels, there are two preconditions: Firstly, the boss is willing to use the underling; Secondly, the underling is willing to accept the order from their boss. From the certain point of view, due to the more complicated emotion of the underline locating at the lower position, the will of the underline is more important and difficult than that of the boss. Hence, the employers should correctly find out the employees' innermost feelings to conquer the employees' heart and make them trust you, respect you, love you and work for you. However, it is a hard job. For instance, Bei Liu asked Liang Zhuge to take up a responsible post repeatedly and was neglected by Liang Zhuge in the beginning. Until affected by his persistence and courtesy, Liang Zhuge was jumped at his invitation to help him to revive Han. Afterwards, Liang Zhuge spared no effort in the performance of his duty and worked for Bei Liu to the end of his days.

Tactics of leading the talents include making a psychological attack as priority, unpredictable activities, conquering 
opponents separately, showing falsehood and hiding truth, conquering the opponents by getting rid of their following, seizing the head firstly, applying the benefits and punishments together, punishing someone as a warning to others, forgiving the defects of the employees, placating the world and wining without war.

\subsection{As the basic point of using the talents, the employers have to retain the talents.}

The key point of retaining the talents is to keep the soul of the talents with the precondition of knowing his soul. Retaining the talents means retaining the talents who are needed by the employers in the activities of using the talents. It contains three aspects:

Firstly, retain the talents with salary. The employer can attract and retain the talents by offering better salary and eliminating their worries constantly which is the basic condition of retaining the talents.

Secondly, retain the talents with emotional care. The employer can attract and retain the talents by the emotional communication with each other and satisfying emotional request of the talents. As a Chinese special way to retain the talents, Chinese intellectual has the traditional concept like "soldier will die for the man who knows his soul". Therefore, the employers of the Chinese state company should think about this way more often to retain the talents.

Thirdly, retain the talents with bright career prospect. The employers can attract and retain the talents with not only the development of the employers' own career but also satisfying the individual development of the talents. It contains two meanings: (1) The development of the employers' career; (2) The individual development of the talents. Only if the employers have the bright career prospect and the talents can fully and healthily develop, the talents can be attracted and held stably. The moral of the talents can also be inspired and enhanced. Further, the talents can work for the employer with all his heart. Therefore, as one of the strategies of retaining the talents, providing the bright career prospect is the most important issue.

For example, "good horse eats grass back". Different companies have the widely divergent attitudes towards the resigned employees. Some companies will never hire these ex-employees. According to the data base which has the record of each employee, whenever and wherever the employee resigned from any of department or branch, he will never be allowed to enter into this company again. However, other companies have the totally contrast attitudes towards the resigned employees. They are glad to re-cooperate with these ex-employees by overcoming the past enmity, as long as these ex-employees have the abilities to work for the company.

There are several reasons why so many CGO agree this kind of strategy to retain the talents just like "good horse eats grass back". Firstly, by means of re-cooperation and frankly communication, the company can understand the real reason of the resign. Hence, the manager can take the specific strategies to retain the talents. Secondly, the employees normally have complicated circumstance which leads them to resign. Most of these reasons are disappointing relationship with colleagues, superiors and subordinates, unhappy emotion with work position. However, so many changes have happed by now. Hence, re-cooperating is beneficial to both of the employers and employees. Thirdly, even though these guys were sacked by the employers, they are familiar with the aspects of the company. So, they can work for the company immediately without training which results in low cost. Finally, considering the trend like more and more job-hopping and selecting career with more individual concern, it is a good option to re-cooperate with the ex-employees without pay too much attention to their backgrounds.

Retaining talents contains job-shifting within the company, 100\% trust, emotional care, heart-contract better than paper-contract, good horse eats grass back and special tasks and so on.

\subsection{The strategy of training is the basic issue of using the talents.}

Training is the basic method to develop and improve the intelligence and quality of the employees. It is the method of communication between the employers and the employees in terms of the knowledge and emotion. Further, it is the basic guarantee of the success of the future career. The strategy of training means how to train and teach the talents, which contains two aspects: (1) Training the talents; (2) Teaching the talents, which is the organic combination of profound training, thought and strategies of teaching talents.

For example, 'teaching students in accordance of their aptitude'. This idiom comes from The Analects-Yong Ye:" $\mathrm{Zi}$ says: 'The advanced knowledge can only be taught to the students with high quality."'. As quote in Zhuxi Collection, Jingfu Zhang said:" There is no difference between the profound and superficial principle of the sage. However, different training should be afforded to different students in accordance with their aptitude." It is based on the fully understanding of the their personality.

Kong zi claims that he has 3,000 students and 72 wisdoms. Why can he achieve such a great success? The reason is strongly due to his fully understanding and properly teaching his students. According to his saying" Cai is fool, Can is rude, Shi is prejudiced......" it can be seen that he knows his students like the palm of his own hand. 
Lun Yu Xianjin recorded such an example: Zilu, Kongzi’s student, asked him:” Do I have to exactly follow what I heard?" Kongzi answered:" How can you do it without considering the opinions of your father and brothers? "However, when another student, Ran, asked him the same question, Kongzi gived him a totally different answer:" Yes, does what you heard." At the moment, another student, Gong Xihua, felt confused:" Why did you give two different answers for the same question?" Kongzi said:" Ran hesitates to make a decision, so I encourage him to go ahead. While, Zilu is a rude person, so I have to put him a little bit backward."

For the employers of the time, the up-to-date meaning of 'teaching students in accordance of their aptitude' is to afford different training to different employees. For example, for the employees having poor mentality, the employers should improve their mental quality. For the employees lacking of knowledge, the employers should improve their knowledge.

The strategy of training includes: Faith training; Persistent learning; Teaching students accordance of their aptitude; Acting is better than knowledge; Subtle influence and.

\section{Significance of Studying on Tactics in Using Talents}

Tactics in using talents is the one of the basis condition of achieving successful career. Further, it is the combination of various scientific knowledge and the sublimation of experience and art of using talents. Therefore, it has being significantly concerned by not only politician, ideologist, militarist and strategist but also ordinary people. Learning and studying the tactics in using talents can enhance the understating of art, knack and tactics in using talents. It also can raise the art of using talents up to a higher conception which would establish the basis for overcoming the difficulties, defeating the opponents, leading and using talents.

\section{References}

Bai, Sha \& Lu, Jinglin. (1992). Emperors' Excellent Schemes. Jinan, Shandong Friendship Publishing Company, Dec.

Chai, Yuqiu. (1990). Strategies Collection. Beijing, Blue Sky Press, June.

Chai, Yuqiu. (1992). Strategies Collection (Continued). Nanning, Guangxi People's Publishing House, June.

Feng, Menglong. (1994). All Schemes. Beijing, China Superexcellent Publishing House, Dec.

Wang, Yuanrui, (1989). Art in Modern Personnel Management. Beijng, China University of Political Science and Law Press, Feb.

Zhou, Zhiming. (1991). Excellent Schemes. Beijing, Tidal Press, Jan. 